\title{
Developmental enamel defects and other oral problems in children with microcephaly associated with fetal exposure to zika virus (ZIKV)
}

\begin{abstract}
Introduction: Children with microcephaly as a result of fetal exposure to the Zika virus (ZIKV) may experience brain changes, neurological abnormalities, bone and craniofacial deformities. Objective: The objective of this study was to describe oral problems and oral health habits involving children in early childhood with microcephaly associated with fetal exposure to ZIKV.

Methodology: A cross-sectional study was carried out on a sample of children with microcephaly, exposed to ZIKV during the pregnancy, attended at the Neuropediatrics outpatient clinic of a reference center in Salvador-BA. Clinical examination of oral conditions and interviews with mothers/ guardians were performed to obtain sociodemographic data and lifestyle habits. A descriptive analysis of the variables and exploratory analysis of factors associated with defects in enamel development (DDE) were done using Pearson's chi square and a significance level of $5 \%$.

Results: 74 children participated in the study and a higher frequency of the following oral conditions was observed: delayed eruption chronology $(100 \%)$, dental biofilm $(55.88 \%)$ and enamel defects (DDE) $(22.06 \%)$. Bohn nodules $(6.85 \%)$, micro dents $(2.70 \%)$ and ectopically positioned dental elements $(1.35 \%)$ were less frequent. Only one of them showed incipient caries lesion (1.47\%). The occurrence of DDE was more frequent among those with ogival palate, normal weight at birth and who did not have an eruptive delay (p $<0.05$ ). In oral habits, $52.70 \%$ used a pacifier, $50 \%$ feeding at night, $66.22 \%$ used sugar and $52.24 \%$ brushed teeth before bed
\end{abstract}

Conclusion: Monitoring oral health conditions is necessary to minimize oral health problems in these children

Keywords: microcephaly, zika virus, oral health, children
Volume 6 Issue 3 - 2020

\author{
Erica Santana D Agostino,' Janeusa Rita \\ Leite Primo Chagas, ${ }^{2}$ Tatiana Frederico de \\ Almeida, ${ }^{3}$ Maria Beatriz Barreto de Sousa \\ Cabral, ${ }^{3}$ Maria Cristina Teixeira Cangussu, ${ }^{3}$ \\ Maria Isabel Pereira Vianna ${ }^{3}$ \\ 'Master in Dental Health in Federal University of Bahia,Brazil \\ ${ }^{2}$ Doctor in Santo Antônio Hospital, Neuropediatric ambulatory, \\ Brazil \\ ${ }^{3}$ Professor in School of Dentistry UFBA, Brazil
}

Correspondence: Maria Cristina Teixeira Cangussu,Professo in School of Dentistry / UFBA, Araújo Pinho avenue, 6th floor, 62 Canela. Salvador- BA,Brazil, Email cangusu@ufba.br

Received: May 17, 2020 | Published: June 17, 2020

\section{Introduction}

The Zika Virus (ZIKV) outbreak in Brazil, especially in the Northeast region in the years 2015-2016, involving the infection of women during the pregnancy, revealed its high teratogenic power, causing an increase in newborn with microcephaly and with serious changes congenital. ${ }^{1,2}$ Epidemiological data published by the Health Ministry of Brazil, referring to the epidemiological weeks 45/2015 and $26 / 2017$ (11/8/2015 to 7/1/2017), registered 2,844 cases (using clinical- epidemiological criteria) of Zika virus, $20.1 \%$ of which were later confirmed (sorologic), and 157 of them were classified as likely to be related to congenital infection during pregnancy. Of these, the state of Bahia had the largest number of cases $(17.2 \%){ }^{2}$ Some clinical findings in children with microcephaly associated with ZIKV have already been published, such as brain changes, neurological abnormalities, ${ }^{3}$ bone and craniofacial deformities. ${ }^{4-8}$ Changes have also been reported in children with microcephaly caused by other causes, for example, impaired vision and hearing, delayed cognitive, motor and speech development ${ }^{8,9}$ and epilepsy. ${ }^{10}$

However, there are few studies describing the types and severity of oral changes in children with microcephaly associated with ZIKV. There are reports of the occurrence of tooth eruption delay and changes in the eruption sequence $e^{6,8}$ lip hypotonia, absence of lip sealing and mouth breathing ${ }^{3}$ and enamel opacity. ${ }^{5,8}$ Carvalho et al., ${ }^{11}$ described that, in a population of 30 children with this condition,
$20 \%$ had inadequate tongue position at rest and also registered the presence of short labial or lingual curb, micrognathia, changes in the shape or number of teeth and spasms muscle.In addition to bone development, systemic, local or hereditary disorders that occur during enamel development can cause anomalies in its structure, affecting deciduous and / or permanent dentition ${ }^{12-14}$ and these dental enamel development defects (DDE) predispose to a greater risk of dental caries. ${ }^{15,16}$ According toLunardelli\& Peres ${ }^{17}$ the extent of the defect will depend on factors such as intensity and duration of the etiologic agent and period of crown formation. ${ }^{18}$

Sociodemographic variables, such as low maternal education and low family income, are considered factors associated with enamel changes. ${ }^{19}$ Maternal disorders such as malnutrition and lack of vitamin $\mathrm{A}$, which is responsible for the immune function and growth of ameloblastic cells, calcium and phosphorus deficiency, as well as other systemic events (diabetes, hypertension, congenital syphilis, exanthematic diseases), traumatic, environmental or genetic, can alter the cellular architecture and metabolism during the deposition of the organic matrix causing defects in the enamel structure. ${ }^{12-14} \mathrm{In}$ addition, other events have also been associated with DDE in recent investigations: the use of laryngoscope and endotracheal intubation, prolonged mechanical ventilation and oral tube nutrition, mandibular fractures, surgical trauma, and repair of cleft lip and palate ${ }^{19}$ in addition to prematurity and low weight. ${ }^{20,21}$ Thus, the objective of this study was to describe oral problems and oral health habits in children 
in early childhood with microcephaly associated with fetal exposure to the ZIKV and to verify factors potentially associated with the occurrence of DDE in this population.

\section{Methodology}

A descriptive cross-sectional epidemiological study was carried out, whose data collection took place from April to November 2017, involving all children diagnosed with microcephaly due to fetal exposure to the ZIKV, seen at a reference center in Salvador, Bahia, Brazil, in the Neuropediatrics sector.Possible access to the patients' medical records in the Institution's database, children diagnosed by the medical team were identified as having microcephaly due to fetal exposure to the ZIKV. Children with microcephaly due to other congenital infections and/ or genetic syndromes were excluded from this research. During the regular follow-up consultation, the mother (or guardian) was informed of the research and invited to participate, by signing a free and informed consent form.Primary data were obtained through interviews with mothers and clinical dental examination of children. There was no need for a specific call for the data collection for this study, as the procedures were conducted in the routine consultation, previously scheduled by the sector of the reference center itself.Interviews were conducted with the mother (or guardian), with the application of a structured questionnaire to obtain sociodemographic information and others related to the children's oral health, including sex, age of the child and mother, responsible for the child's care, place of residence (capital or countryside), breastfeeding (type and characteristics), oral hygiene habits, pacifier use, digital suction and mouth breathing.

Subsequently, the children underwent a clinical dental examination by a trained dentist professional to observe aspects related to oral health. Inspection and palpation of the gingival tracts, oral floor, cheek mucosa, tongue regions, soft and hard palate and vestibule bottom were performed. The purpose of the examination was also to identify congenital and developmental oral changes in babies such as Bonh's nodules, Epstein's pearls, dental cysts and cleft palate. Other lesions commonly found in this age group were also investigated, such as herpetic stomatitis and candidiasis. In addition, tongue brake and tongue shape were evaluated and classified according to their insertion and shape according to the protocol proposed by Martinelli et al. ${ }^{22}$ The clinical evaluation of caries used the $\mathrm{dmft}$ index recommended by the World Health Organization (WHO) (Table 1), covering the components: decayed teeth (d), teeth extracted by caries (m) and filled teeth (f $)^{23-25}$ and the presence of stain white tooth decay according to the criteria of Nyvad et al. ${ }^{24}$

Dental enamel changes (DDE) were evaluated based on the criteria defined by Seow ${ }^{16}$ for the presence or absence of enamel hypoplasia and / or enamel hypocalcification, as well as tooth size and position. The evaluation regarding gingival inflammation and dental calculus was based on clinical evaluation through visual inspection. It was considered an inflamed gum when it had redness, edema and / or bleeding. For dental calculus, their presence or absence was recorded (Table 1).

Table I Definition of the variables analyzed in the children's oral clinical examination, Salvador-BA, 20 I7

\begin{tabular}{|c|c|}
\hline \multicolumn{2}{|l|}{ Variables } \\
\hline Soft tissue conditions categorization & Categorization \\
\hline Bonh nodules & 0-absent I-present 9-NR \\
\hline Epstein pearls & 0-absent I-present 9-NR \\
\hline Location of soft tissue lesion & $\begin{array}{l}\text { 0-does not apply I-tongue } 2 \text {-vestibule bottom 3-buccal floor 4- buccal mucosa 5-labial } \\
\text { mucosa 6-hard palate } 7 \text {-soft palate 9-NR (no response) }\end{array}$ \\
\hline Resting lips posture & 0- closed lips I-parted lips 2- open lips 3- other / specify 9-NR \\
\hline Tongue positioning during crying & 0-High tongue I-midline tongue 2-low tongue 3- other / specify 9-NR \\
\hline Tongue shape & 0-Round or square I- slight crack in the tip 2-shape of 3- other / specify 9-NR \\
\hline Visualization of Lingual Brake & 0- possible to view I- impossible to view 9-NR \\
\hline Lingual Brake Thickness & 0- thin I- thick 9-NR \\
\hline $\begin{array}{l}\text { Fixation of the frenulum on the sublingual } \\
\text { (ventral) surface of the tongue }\end{array}$ & 0- middle plane I- middle plane and apex 2- at the apex 9-NR \\
\hline $\begin{array}{l}\text { Fixation of the frenulum on the floor of the } \\
\text { mouth }\end{array}$ & 0-Visible from the sublingual caruncles I- visible from the lower alveolar crest 9-NR \\
\hline Herpetic gingivostomatitis & 0-absent I-present 9-NR \\
\hline Candidiasis & 0-absent I-present 9-NR \\
\hline Orofacial Slits & 0-absent I-Cleft Lip 2-Cleft palate 3-Cleft lip and palate 9-NR \\
\hline Palate shape & 0 -normal I-changed \\
\hline Determination of facial pattern & $\begin{array}{l}\text { 0-dolichocephalic I-mesocephalus 2-brachycephalic 3-turricephalus 4-plagiocephaly } \\
\text { 5-scalophalocephalus }\end{array}$ \\
\hline \multicolumn{2}{|l|}{ Periodontal Conditions } \\
\hline Gingival inflammation & 0-absent I-present 9-NR \\
\hline Presence of dental calculus & 0-absent I-present 9-NR \\
\hline
\end{tabular}


Table Continued...

\begin{tabular}{|c|c|}
\hline \multicolumn{2}{|l|}{ Variables } \\
\hline Soft tissue conditions categorization & Categorization \\
\hline \multicolumn{2}{|l|}{ Dental Conditions } \\
\hline Dental units present in the arcade & Specify erupted teeth \\
\hline Decayed teeth & Number of decayed teeth \\
\hline Lost teeth & Number of missing teeth \\
\hline Filled teeth & Number of filled teeth \\
\hline dmf-t index & Average decayed, lost and filled teeth \\
\hline Dental biofilm & 0-absent I- present 9-NR \\
\hline Incipient carious lesion & 0-absent I- present 9-NR \\
\hline Enamel development defect (DDE) & 0-no change I- hypoplasia 2- hypocalcification 3- hypoplasia and hypocalcification 9-NR \\
\hline Change in position of teeth & 0-normal I- ectopic (specify teeth) 9-NR \\
\hline Change size of teeth & 0-normal I- abnormal 9-NR \\
\hline
\end{tabular}

The examination was performed by a single professional dentist trained in a lighted environment, using stretchers available on site. Following bio safety rules, disposable gloves per child, mask, cap and apron were used, as well as individual wooden spatulas for viewing the oral cavity and / or sterile gauze. A descriptive analysis of the variables of interest was performed, obtaining the simple frequency for the categories and measures of central tendency and dispersion for the continuous ones. In the other way, for categorical variables, differences in the occurrence of enamel development defects were analyzed according to variables of interest, using Pearson's chisquare, adopting in all cases the 5\% level for establishing the statistical significance.This research was approved by the Ethics Committee of the School of Dentistry of the Federal University of Bahia, CAAE No. 2.005.322.

\section{Results}

During the period, 111 children from a universe of 183 were examined at the reference center. Considering the criteria adopted in this study, 37 children were excluded: 28 had a history of fetal exposure to ZIKV, but had a normal head circumference at birth; six children were diagnosed with microcephaly, but had positive serology for other congenital infections; and three children diagnosed with microcephaly, also had characteristics of other genetic syndromes. The study population, therefore, consisted of 74 children diagnosed with microcephaly and a history of fetal exposure to ZIKV. The children's age ranged from 2 to 24 months, with a mean age of 17.7 months $(\mathrm{SD} \pm 3.6)$, with a predominance of 18 -month-old children $(18.9 \%)$, female $(60.81 \%)$ and brown or black $(80.28 \%)$. The results regarding the family sociodemographic characterization showed that the mothers' age at the time of the medical interview was between 15 and 34 years, with an average of 27.08, $(\mathrm{SD} \pm 6.72)$. Almost all mothers reported being the main responsible for the daily care of the child $(91.89 \%)$ and $29.58 \%$ of them claimed to contribute to the family income. It is worth mentioning that although most children were born in the capital $(58.33 \%)$, the majority lived in the countryside $(56.94 \%)$.

Table 2 shows the results from behavioral factors related to children's eating habits and oral health. Three children had been fed by gastric tube since birth. As for the others, $36.49 \%$ of mothers reported exclusive breastfeeding before 06 months. After 06 months, artificial feeding was the most common $(60.27 \%)$. In oral hygiene habits, most mothers reported brushing children's teeth more than once a day $(79.41 \%)$ and $52.24 \%$ said they brushed before bed. The hygiene of the gingival was also recorded by most mothers (or guardians) $(81.08 \%)$. The use of sugar in infant feeding was reported by $66.22 \%$ of mothers. $52.70 \%$ of mothers confirmed the use of pacifiers by the child, although only $13.51 \%$ reported the habit of digital sucking. In addition, $39.19 \%$ of mothers considered their children mouth breathers.

Table 2 Daily habits related to food and oral health care for children monitored at the reference service of Neuropediatrics, Salvador-BA; $(n=74)$

\begin{tabular}{|c|c|c|}
\hline Variables & $\mathbf{n}$ & $\%$ \\
\hline \multicolumn{3}{|c|}{ Breastfeeding before 06 months } \\
\hline Natural & 27 & 36.49 \\
\hline Artificial & 23 & 31.08 \\
\hline Mixed & 21 & 28.38 \\
\hline Gastric feeding & 3 & 4.05 \\
\hline \multicolumn{3}{|c|}{ Breastfeeding after 06 months } \\
\hline Natural & 4 & 5.48 \\
\hline Artificial & 44 & 60.27 \\
\hline Mixed & 22 & 30.14 \\
\hline Gastric feeding & 3 & 4.11 \\
\hline \multicolumn{3}{|l|}{ Night feeding } \\
\hline No & 37 & 50 \\
\hline Yes & 37 & 50 \\
\hline \multicolumn{3}{|l|}{ Use of sugar } \\
\hline No & 25 & 33.78 \\
\hline Yes & 49 & 66.22 \\
\hline \multicolumn{3}{|c|}{ Frequency of oral hygiene on the day* } \\
\hline One or more times & 54 & 79.41 \\
\hline None & 14 & 20.59 \\
\hline
\end{tabular}


Table Continued...

\begin{tabular}{lll}
\hline \multicolumn{1}{l}{ Variables } & n & $\%$ \\
\hline Brushing before sleep at night* & \\
Yes & 35 & 52.24 \\
No & 32 & 47.76 \\
Rim oral hygiene & & \\
Yes & 60 & 81.08 \\
No & 14 & 18.92 \\
Use of a pacifier & & \\
No & 35 & 47.3 \\
Yes & 39 & 52.7 \\
Finger sucking habit & & \\
No & 64 & 86.81 \\
Yes & 10 & 13.51 \\
Use of mouth Breather & & \\
No & 45 & \\
Yes & 29 & \\
\hline
\end{tabular}

* Lost or undeclared information

The evaluation of dental structures was carried out in 68 children since 06 of them had not started the dental eruptive process at the time of the oral examination. Graph 1 shows the distribution of the number of teeth per dental element in the study population. Units 55, 65 and 85 had not erupted in any of the children and only one tooth of element 75 was registered.

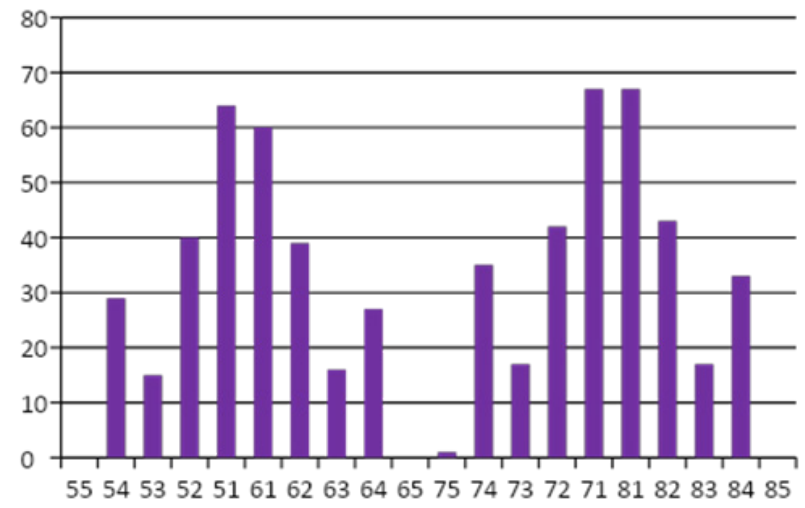

Graph I Number of teeth present according to the dental unit in children monitored at the reference service of Neuropediatrics, Salvador-BA. $(n=74)$.

The $\mathrm{dmft}$ found was zero. The presence of incipient caries lesion was registered in a single patient $(1.47 \%)$ in units 51 and 61 . Of the total, $2.70 \%$ of the children had some small teeth and $1.35 \%$ had some ectopically positioned dental element.Regarding the presence of dental biofilm, $55.88 \%$ of the children were present in the canine and molar regions. As for the gingival condition, two children $(2.70 \%)$ had gingival inflammation and two children $(2.70 \%)$ had supragingival dental calculus.During the examination, $41.89 \%$ of the children had completed lip sealing, while $37.84 \%$ had parted lips and $20.27 \%$ opened lips. The evaluation of the tendency of the behavior of the tongue during crying, was only possible to be observed in 25 children, who expressed this behavior during the clinical examination.
In thisone, it was possible to show that $24 \%$ of the children had a tongue in an elevated position, $36 \%$ in an average position while $40 \%$ in a low plane. It was found that $26.76 \%$ of the children did not have a lingual brake. The results of the characterization of the lingual brake are described in Table 3. Regarding changes in soft tissue, a single child $(1.37 \%)$ presented ulcers in the bottom of the vestibule. Among the other alterations investigated, which could occur in early childhood, the presence of Bohn's Nodules $(6.85 \%)$ was observed; inclusion cysts, Epstein pearls and dental cysts were not found in this study. There was no occurrence of natal or neonatal teeth. The cleft lip and palate, present in 01 children, was characterized as median (Table 3).

Table 3 Characterization of the lingual brake according to the classification of Martinelli et al., ${ }^{22}$ congenital and developmental oral alterations and other oral lesions of children in early childhood followed at the Neuropediatrics outpatient clinic, Salvador-BA, 20I7; $(n=74)$

\begin{tabular}{lll}
\hline Variables & $\mathbf{n}$ & $\%$ \\
\hline Presence of lingual brake & 52 & 73.24 \\
Yes & 19 & 26.76 \\
No & & \\
Thickness of lingual brake* & 43 & 82.69 \\
Slender & 9 & 17.31 \\
Thick & 9
\end{tabular}

Fixation of the frenulum on the sublingual (ventral) side of the tongue*

\begin{tabular}{|c|c|c|}
\hline Middle plane & 47 & 90.38 \\
\hline Middle plane and apex & 4 & 7.69 \\
\hline At apex & I & 1.92 \\
\hline \multicolumn{3}{|c|}{ Fixation of the frenulum on the floor of the mouth* } \\
\hline Visible from sublingual caruncles & 49 & 94.23 \\
\hline Visible from the lower alveolar crest & 3 & 5.77 \\
\hline \multicolumn{3}{|l|}{ Bonh nodules* } \\
\hline Absent & 68 & 93.15 \\
\hline Present & 5 & 6.85 \\
\hline \multicolumn{3}{|l|}{ Rash hematoma* } \\
\hline No & 71 & 97.26 \\
\hline Yes & 2 & 2.74 \\
\hline \multicolumn{3}{|l|}{ Orofacial slits } \\
\hline Absent & 73 & 98.65 \\
\hline Cleft lip & - & - \\
\hline Cleft palate & - & - \\
\hline Cleft lip and palate & I & 1.35 \\
\hline \multicolumn{3}{|l|}{ Geographic tongue* } \\
\hline No & 71 & 97.26 \\
\hline Yes & 2 & 2.74 \\
\hline
\end{tabular}


Table Continued..

\begin{tabular}{lll}
\hline Variables & $\mathbf{n}$ & $\%$ \\
\hline Herpetic gingivostomatitis* & 73 & 100.00 \\
Absent & - & - \\
Present & & \\
Candidiasis* & & \\
Absent & 72 & 98.63 \\
Present & 1 & 1.37
\end{tabular}

*Lost or undeclared information
Regarding the evaluation of the DDE, it was possible to verify that 15 children (22.06\%) had some types of defect, being 08 cases in the female sex. Dental units 51 and 61 were the most affected. Hypocalcification was more prevalent with $20.59 \%$. No occurrence of isolated dental hypoplasia was recorded, only one child had the presence of both changes that is the presence of hypoplasia and hypocalcification $(1.47 \%)$, in units 51 and 61. Graph 2 shows the percentage distribution of children according to the number of teeth affected by DDE. Analyzing differences in the occurrence of DDE, according to variables of interest (Table 4), statistical significance $(\mathrm{p}<0.05)$ was observed when considering the shape of the palate, birth weight, and eruption chronology. Thus, there was a higher occurrence of DDE among children with ogival palate, normal weight at birth and who didn't have an eruptive delay.

Table 4 DDE occurrence according to variables of interest in children monitored at the reference service of Neuropediatrics, Salvador-BA; $(n=74)$

\begin{tabular}{|c|c|c|c|c|c|}
\hline \multicolumn{6}{|c|}{ DDE } \\
\hline \multirow[t]{2}{*}{ Variables } & \multicolumn{2}{|c|}{ Absent } & \multicolumn{2}{|c|}{ Present } & \multirow[b]{2}{*}{ p*Value } \\
\hline & $\mathbf{n}$ & $\%$ & $\mathbf{n}$ & $\%$ & \\
\hline \multicolumn{6}{|l|}{ Sex } \\
\hline Girls & 32 & 80 & 8 & 20 & 0.63 \\
\hline Boys & 21 & 75 & 7 & 25 & \\
\hline \multicolumn{6}{|l|}{ Coulor of skin } \\
\hline White & 9 & 69.2 & 4 & 30.8 & 0.44 \\
\hline Black or brown & 42 & 79.2 & 11 & 20.8 & \\
\hline \multicolumn{6}{|c|}{ Trimester of congenital zika vírus infection } \\
\hline 10 trimester & 21 & 80.77 & 5 & 19.23 & 0.95 \\
\hline $2^{\circ}-30$ trimester & 22 & 81.49 & 5 & $18.5 \mid$ & \\
\hline \multicolumn{6}{|l|}{ Palate shape } \\
\hline Normal & 22 & 95.45 & 1 & 4.55 & 0.02 \\
\hline Ogival & 31 & 70.45 & 13 & 29.55 & \\
\hline \multicolumn{6}{|c|}{ Use of $\mathrm{O}_{2}$ in the maternity } \\
\hline No & 46 & 76.67 & 14 & 23.33 & 0.7 \\
\hline Yes & 5 & 83.33 & 1 & 16.67 & \\
\hline \multicolumn{6}{|c|}{ Use of incubator in maternity } \\
\hline No & 41 & 5.92 & 13 & 24.08 & 0.39 \\
\hline Yes & 8 & 88.89 & 1 & 11.11 & \\
\hline \multicolumn{6}{|l|}{ Birth weight (g) } \\
\hline Equal or more 2500 & 35 & 71.42 & 14 & 28.58 & 0.04 \\
\hline Less than 2500 & 18 & 94.73 & 1 & 5.27 & \\
\hline \multicolumn{6}{|l|}{ Exanthematic disease } \\
\hline No & 9 & 69.23 & 4 & 30.77 & 0.4 \\
\hline Yes & 44 & 80 & 11 & 20 & \\
\hline \multicolumn{6}{|c|}{ Chronology of eruption (eruptive delay) } \\
\hline No & 21 & 67.75 & 10 & 32.26 & 0.04 \\
\hline Yes & 32 & 86.50 & 5 & 13.5 & \\
\hline
\end{tabular}

*Qui- Square test of Pearson 


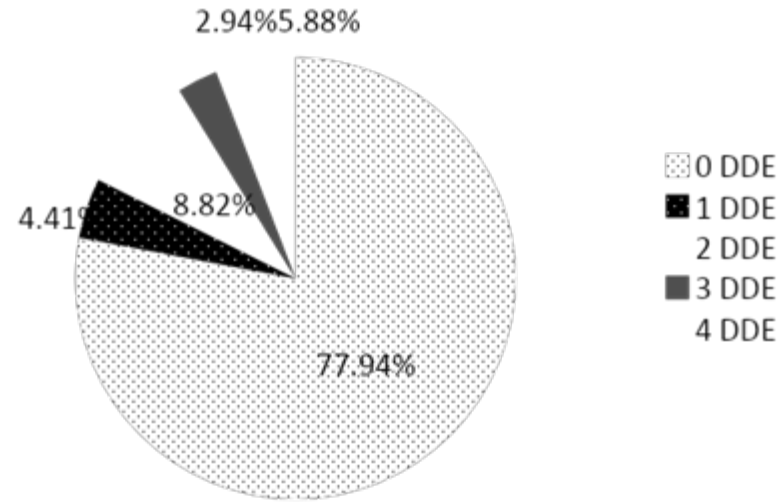

Graph 2 Percentage distribution of children according to the number of teeth affected by DDE at the reference service of Neuropediatrics, SalvadorBA. $(n=74)$.

\section{Discussion}

Investigating the occurrence of orofacial problems in children with microcephaly due to congenital ZIKV infection is important to enable comprehensive knowledge about the development of them and guide effective actions of an interdisciplinary intervention. However, studies focusing on this issue are still scarce in the literature. ${ }^{4-8}$ As a result, the possibilities of interation with the literature are limited, making it often necessary to discuss the results from data observed in child. ${ }^{23}$

Thus, unlike studies that analyzed a similar age range in the general population, ${ }^{24-27}$ the occurrence of dental caries was not observed in this study. However, it is worth noting that the presence of known risk factors for early caries, such as the use of sugar, night meals, the presence of biofilm and DDE, has been identified and that, if protective measures are not adopted, tooth decay can be quickly reach primary dentition. Cabral et al. ${ }^{26}$ in a prospective cohort study involving the monitoring of children aged 4-30 months for 14 months, observed that the average dmft tripled at the end of the follow-up. Nóbrega et al., ${ }^{27}$ in the municipality of Teresina, state of Piauí, found a prevalence of caries of $50.20 \%$ among the 566 children examined, all of whom were older, with 60 months of age.It was possible to observe the early occurrence of gingival inflammation $(2.7 \%)$ and dental calculus $(2.7 \%)$ in this population. Palma et al. ${ }^{28}$ evaluating 5 -year-old children, observed a similar prevalence regarding gingival inflammation (2.8\%), however, the prevalence of dental calculus was only $0.4 \%$. Other works, such as Granville-Garcia et al., ${ }^{29}$ involving children from 1 to 5 years old, had a higher prevalence (10.9\%), in relation to gingivitis.

Del Campo et al., ${ }^{30}$ reported the observation of the tongue brake in 11 children out of 83 with microcephaly due to fetal exposure to the ZIKV, and 04 children did not have a tongue brake. In the work of these authors, there is no mention of the characterization of the lingual brake of the other 07 children, nor the condition of the other 72 children. In this study, a higher prevalence was found, observing $26.76 \%$ of the children with absence of the lingual brake.

Among the congenital developmental changes that can occur in early childhood, Bonh's Nodules were more frequent in this study, with a prevalence of $6.85 \%$. As for the other types of inclusion cysts, there was no record of Epstein's pearl or cyst of the dental lamina. This result is compatible with the findings by Santos et al., ${ }^{31}$ who found a prevalence of $6.23 \%$ when studying inclusion cysts.
When analyzed separately, it is observed that, in general, the Bonh Nodules are more frequent and the prevalence varies greatly between studies, as observed in the works of Gomes, Jesus \& Novais ${ }^{32}$ (89.2\%), Aguiar et al., ${ }^{33}$ and Pieruccini Arias $^{34}$ (11.92\%). Regarding Epstein's pearls, they were also not registered in the works of Gomes, Jesus \& Novais, ${ }^{32}$ however they had a prevalence of $3.36 \%$, in the work of Pieruccini Arias. ${ }^{34}$ The dental lamina cysts were found in the investigation by Gomes, Jesus ${ }^{32}$ with a prevalence of $5.4 \%$. The two other congenital developmental disorders most prevalent in the study were rash hematomas and geographical tongue, both with a frequency of $2.74 \%$. The rash hematoma considered a change of high prevalence in this age group in children with exposure to ZIKV by Silva et al., 5 $(53.84 \%)$, was rare in the study by Almeida et al., ${ }^{35}(0.9 \%)$ and did not occur in this study.

Another alteration found in children was the cleft lip and palate, with a prevalence of $1.74 \%$. The study conducted by Zen et et al. ${ }^{36}$ verified the marked presence of cleft palate and / or lip in children with Edwards Syndrome, just as Sisodia et al. ${ }^{37}$ found in individuals with Seckel Syndrome.The prevalence of oral candidiasis in this study was $1.74 \%$, considered low when compared to the studies by Yilmaz et al. ${ }^{38}$ who cite oral candidiasis as the most prevalent change in their results among other pathologies common to early childhood, with $10.70 \%$. As in the results by Cruz et al. ${ }^{39}$ who found a prevalence of $5.45 \%$ of pseudomembranous candidiasis, with $8.86 \%$ in children aged 3-6 years when compared to other age groups. In the present study, there was no record of natal or neonatal teeth, also differing from the results found by Santos and et al., ${ }^{31}$ who pointed out a prevalence of $0.65 \%$ in their study. Even higher prevalence rates were reported by Pieruccini $\operatorname{Arias}^{34}(3.08 \%)$. Silva et al., ${ }^{5}$ reported the presence of supernumerary teeth in children exposed to the ZIKV.40

The presence of DDE in children with fetal exposure to ZIKV, was observed in this research with a prevalence of $22.06 \%$. Other studies have also reported this finding. The study by Siqueira et al., ${ }^{8}$ analyzed the prevalence of DDE in primary dentition in children with microcephaly due to fetal exposure to the ZIKV, describing a proportion of $12.19 \%$. Gusmão et al., ${ }^{4}$ and Silva et al., ${ }^{5}$ also verified the presence of opacities and hypoplasia in these children, with a prevalence of $28.10 \%$ and $30.76 \%$, respectively.In the case of congenital syndromes, it is observed that hypoplasia is a very common DDE. ${ }^{37,38}$ In this study, however, the greatest occurrence of changes in enamel development was represented by hypocalcification, with a prevalence of $20.59 \%$. No alteration of the isolated hypoplasia type was observed, with only $1.47 \%$ of hypoplasia associated with hypocalcification.

When the results are compared to epidemiological studies that analyzed DDE in primary dentition, the prevalence in this study is higher than the results presented by Huang et al., ${ }^{41}$ who found an occurrence of $6.1 \%$. However, the prevalence observed here was lower, when compared to the results of Hoffman, Souza \& Cypriano ${ }^{43}$ who found $29.6 \%$ of children with DDE..$^{42}$ The literature reveals that DDE can predispose to tooth decay, tooth sensitivity, malocclusion and aesthetic problems in preschoolers. ${ }^{12,18}$ Its etiology is multifactorial and can be caused by genetic alterations and environmental factors, acquired after birth, such as infectious diseases. ${ }^{16}$

Some studies indicate that gestational time and birth weight can interfere with the prevalence of DDE. The authors report that premature and low birth weight children are at higher risk for the development of enamel defects. ${ }^{20,21}$ In this study, among the children who presented DDE, only one child was premature and gestational age was not associated $(p>0.05)$. In relation to birth weight, in this 
study, the association was statistically significant, however, the results differed from those of the other authors, as children with a weight equal to or greater than 2500 kilos had a higher occurrence of DDE. ${ }^{44}$

It is worth considering the need for future investigations that focus on other possible factors associated with DDE, such as use of medications and nutritional status during pregnancy, or even consider the hypothesis that the ZIKV is capable of directly affecting the amelogenesis process, during the phase of capsule, responsible for the apposition and mineralization of the tissues. The presented study describes from a descriptive epidemiological approach some of the main oral alterations in children with microcephaly exposed to the ZIKV during the pregnancy. Among the advantages of this investigation, we highlight the sample size, the evaluation of different oral diseases and the exploratory analysis of the DDE in search of potential associated factors. However, we emphasize that the findings of the exploratory analyzes must be analyzed with caution, considering the type of study carried out (cross-sectional), which does not guarantee the temporal advance of the exposure in relation to the potential effects.

\section{Conclusion}

In children with microcephaly due to fetal exposure to the Zika virus analyzed there was a significant frequency of delay in the rash chronology (100\%), dental biofilm (55.88\%) and enamel development defects (DDE) (22.06\%). Less incipient lesions of dental caries, gingival alterations, dental calculus, Bohn nodules, small teeth and ectopic teeth were less frequent, with prevalence below $10 \%$. No child had a cavity lesion of dental caries. The occurrence of DDE was shown to be associated with the shape of the palate, the chronology of the eruption and birth weight, being more frequent among those with ogival palate, normal weight at birth and who did not have an eruptive delay. As for the investigated habits, the use of sugar $(66.22 \%)$, night feeding $(50.00 \%)$, the use of pacifiers $(52.70 \%)$ and brushing before bed (52.24\%) were more frequent). These results show the need for periodic dental monitoring and evaluation of children with microcephaly and a history of fetal exposure to Zika virus.

\section{Acknowledgments}

None.

\section{Conflicts of interest}

Author declare that there is no conflict of interest.

\section{Funding}

None.

\section{References}

1. Nunes ML, Carlini CR, Marinowic D, et al. Microcephaly and Zika virus: a clinical and epidemiological analysis of the current outbreak in Brazil. $J$ Pediatr. 2016;92(3):230-240.

2. Brazil. Ministry of Health. Monitoring of changes in Zika infection until Epidemiological Week 20/2017. SUS Epidemiological Report, 2017.

3. Meneses JDA, Ishigami AC, de Mello LM, et al. Lessons Learned at the Epicenter of Brazil's Congenital Zika Epidemic: Evidence From 87 Confirmed Cases. Clin Infect Dis. 2017;64(10):1302-1308.

4. Gusmão TPL, Faria ABS, Leão Filho JC, et al. Dental changes in children with congenital Zika syndrome. Oral Dis. 2020;26(2):457-464.
5. Silva MCPM, Arnaud MA, Lyra MCA, et al. Dental development in children born to Zikv-infected mothers: a case-based study. Archives of Oral Biology. 2020;110:104598.

6. D'Agostino ÉS, Chagas JRLP, Cangussu MCT, et al. Chronology and sequence of deciduous teeth eruption in children with microcephaly associated to the Zika virus. Spec Care Dentist. 2020;40(1):3-9.

7. Khanna R, Gupta MS, Jagga U. Zika virus: A review with oral health implications. J Dent Res Rev. 2017;4:50-52.

8. Siqueira RMP, Santos MTBR, Cabral GMP. Alterations in the primary teeth of children with microcephaly in Northeast Brazil: a comparative study. International J Paediatr Dent. 2018.

9. McElrath TF, Allred EN, Kuban K, et al. Factors associated with small head circumference at birth among infants born before the 28th week. Am J Obstet Gynecol. 2010;203:138.e1-8.

10. França GV, Schuler-Faccini L, Oliveira WK, et al. Congenital Zika virus syndrome in Brazil: a case series of the first 1501 livebirths with complete investigation. Lancet. 2016;388(10047):891-897.

11. Vianna RAO, Lovero KL, Oliveira SA, et al. Children Born to Mothers with Rash During Zika Virus Epidemic in Brazil: First 18 Months of Life. J Trop Pediatr. 2019;65(6):592-602.

12. Carvalho IF, Alencar PNB, Carvalho de Andrade MD, et al. Clinical and $\mathrm{X}$-ray oral evaluation in patients with congenital Zika Virus. J Appl Oral Sci. 2019;27:e20180276.

13. Pascon T, Barbosa AMP, Cordeiro RCL, et al. Prenatal exposure to gestational diabetes mellitus increases developmental defects in the enamel of offspring. PLoS One. 2019;14 (2):e0211771.

14. Akşit Bıcak D, Urgancı N, Akyuz S, et al. Clinical evaluation of dental enamel defects and oral findings in coeliac children. Eur Oral Res. 2018;52(3):150-156.

15. Corrêa-Faria P, Martins-Júnior PA, Andrade RGV, et al. Perinatal factors associated with developmental defects of enamel in primary teeth: a casecontrol study. Braz Oral Res. 2013;27(4):363-368.

16. Massignan, C, Ximenes M, da Silva Pereira C, et al. Prevalence of enamel defects and association with dental caries in preschool children. Eur Arch Paediatr Dent. 2016;17;461- 466.

17. Seow WK. Developmental defects of enamel and dentine: challenges for basic science research and clinical management. Australian Dent J. 2014;59(1 Suppl):143-154.

18. Lunardelli SE, Peres MA. Breast-feeding and other mother-child factors associated with developmental enamel defects in the primary teeth of brazilian children. J Dent Child (Chic). 2006;73(2):70-78.

19. Tourino LFP, Zarzar PM, Corrêa-Faria P, et al. Prevalence and factors associated with enamel defects among preschool children from a southeastern city in Brazil. Science \& Collective Health. 2018;23(5):16671674 .

20. Ribas AO, Czlusniak GD. Dental enamel anomalies: etiology, diagnosis and treatment. UEPG Ci Biol Saude Ponta Grossa (PR). 2004;10 (1):2336.

21. Carvalho-Sauer R, Costa MCN, Barreto FR, et al. Congenital Zika Syndrome: Prevalence of low birth weight and associated factors. Bahia, 2015-2017. International Journal of Infectious Diseases. 2019;82:44-50.

22. Caixeta FF, Corrêa MS. Evaluation of the dental eruption pattern and of enamel defects in the premature. Rev Assoc Med Bras. 2005;51(4):195199.

23. Martinelli RL de C, Marchesan IQ, Berretin-Felix G. Protocol for the evaluation of the lingual frenulum for babies: relationship between anatomical and functional aspects. Revista CEFAC. 2013;15(3):599-610. 
24. World Health Organization- WHO. The World Oral Health Report 2003. Continuous Improvement of Oral Health in the 21st Century - the Approach of the WHO Global Oral Health Program. Geneva: 2003.

25. Nyvad B, Machiulskiene V, Baelum V. Reliability of a new caries diagnostic system differentiating between active and inactive caries lesions. Caries Res. 1999;33:252-260.

26. Assunção LRS, Vilella KD, Rocha DP, et al. Caries epidemiology of children in the primary infancy in the City of Belém, PA. Rev Assoc Paul Cir Dent. 2015;69(1):74-79.

27. Cabral MBBS, Mota ELA, Cangussu MCT, et al. Risk factors for cariesfree time: longitudinal study in early childhood. Rev Saúde Pública. 2017;51:118.

28. Nóbrega AV, Moura LFAD, Andrade NS, et al. Impact of dental caries on the quality of life of preschoolers measured by the PedsQL questionnaire. Collective Health Science. 2019;24(11):4031-4042.

29. Palma ABO, Martins AMEBL, Ferreira RC, et al. Oral health of 5-yearold children in the municipality of Montes Claros, Brazil. Rev Unimontes Cientifica. 2012;14(1):69-82.

30. Granville-Garcia AF, Ferreira JMS, Barbosa AMF, et al. Caries, gingivitis and oral hygiene in preschoolers. RGO Rev Gaúch Odontol. 2010;58(4):469-473.

31. Del Campo M, Feitosa IM, Ribeiro EM, et al. The phenotypic spectrum of congenital Zika syndrome. Am J Med Genet Part A. 2017;173:841-857.

32. Santos FFC, Pinho JRO, Libério SA, et al. Prevalence of congenital oral changes and development in infants aged 0 to 6 months. Rev Odonto Ciencia. 2009;24(1):77-80.

33. Gomes LRG, Jesus NA, Novais RK. Evaluation of maternal perception and frequency of oral changes in newborns at the Regional Hospital of Presidente Prudente-SP. Colloquium Vitae. 2010;2(1):34-40.

34. Aguiar YPC, Cavalcati AFC, Alencar CRB, et al. Chronology of the first deciduous tooth eruption in brazilian children with microcephaly associated with zika virus: a longitudinal study. Brazilian Research in Pediatric Dentistry and Integrated Clinic. 2018;18(1):e3982.
35. Pieruccini Arias SP. Characterization of oral alterations in children aged 0-1 years, born in the hospital of Engativá and attended at the baby clinic of the Fundación HOMI Hospital de la Misericordia Bogotá, DC. A retrospective and prospective study. Otra thesis, Universidad Nacional de Colombia - Bogota Headquarters. 2016.

36. Almeida LHS, Azevedo MS, Fernanda Geraldo Pappen, et al. Rash hematomas: report of three clinical cases in babies. RFO, Passo Fundo. 2015;20(2):222-226.

37. Zen PRG, Rosa RFM, Rosa RCM, et al. Unusual clinical presentations of patients with Patau and Edwards syndrome: a diagnostic challenge? Rev Paul Pediatr. 2008;26(3):295-299.

38. Sisodia R, Raj RK, Goel V. Seckel syndrome: a rare case report. J Indian Soc Pedod Prev Dent. 2014;32(2):160-163.

39. Yilmaz AE, Gorpelioglu C, Sarifakoglu E, et al. Prevalence of oral mucosal lesions from birth to two years. Nigerian J Clinical Practice. 2011;14(3):349-353.

40. Cruz MCFN, Valois EM, Libério SA. Clinical assessment of changes in the oral mucosa in hospitalized children aged 3 to 12 years. $R G O$. 2008;56(2):157-161.

41. Rodriguez-Caballero A, Torres Lagares D, Yanez-Vico RM, et al. Assessment of orofacial characteristics and oral pathology associated with Cri-du-Chat syndrome. Oral Dis. 2012;18(2):191-197.

42. Huang L, Vanstone MR, Hartley T, et al. Mandibulofacial dysostosis with microcephaly: mutation and database update. Human Mutation. 2016;37(2):148-154.

43. I live JS, Marega T, Romagnolo FU. Microcephaly caused by the Zika virus: dental care. Rev Gaúcha Odontol. 2019;67:e2019001.

44. Hoffmann RHS, Sousa MLR, Cypriano S. Prevalence of enamel defects and their relationship with dental caries in primary and permanent dentitions, Indaiatuba, São Paulo, Brazil. Cad Saúde Pública. 2007;23(2):435-444. 